\title{
Size of cervical lesion in locally advanced carcinoma cervix and response to neoadjuvant chemotherapy
}

\author{
Neetu Ahirwar* \\ Department of Obstetrics and Gynecology, Gandhi Medical college Bhopal, Madhya Pradesh, India
}

Received: 24 August 2019

Accepted: 11 October 2019

*Correspondence:

Dr. Neetu Ahirwar,

E-mail: neetuahirwarbharang@gmail.com

Copyright: $\odot$ (the author(s), publisher and licensee Medip Academy. This is an open-access article distributed under the terms of the Creative Commons Attribution Non-Commercial License, which permits unrestricted non-commercial use, distribution, and reproduction in any medium, provided the original work is properly cited.

\begin{abstract}
Background: Recently neoadjuvant chemotherapy has started being considered for advanced stage of carcinoma cervix. Drug delivery to pelvic tumour is optimal with neoadjuvant chemotherapy since tumour vascular supply has not been damaged by any previous pelvic interference. Tumor size and parametrial involvement have been reported to be important predictor of NACT response. Objective of this study was to find out association between size of cervical lesion in locally advanced carcinoma cervix and response to neoadjuvant chemotherapy.

Methods: The present prospective cohort study was carried out in the Department of Obstetrics and Gynaecology with the collaboration of Department of Radiotherapy, Chhatrapati Shahuji Maharaj Medical University Lucknow for a period of 1-year august 2010 to august 2011. 26 patients with histologically proven locally advanced carcinoma cervix were studied. In all cases Cisplatin $75 \mathrm{mg} / \mathrm{m} 2$ and paclitaxel $135 \mathrm{mg} / \mathrm{m} 2$ on day one was given at 14 days interval up to maximum of three courses. Evaluation of operability status was done two weeks after second course of chemotherapy. Those found operable were taken up for radical hysterectomy and rest were given 3rd course of chemotherapy. After two weeks of $3^{\text {rd }}$ course again operability assessment was done and patient was taken up either for surgery or radiotherapy.

Results: It was observed that out of 14 patients who had tumour size $<4 \mathrm{~cm}, 9$ (64.2\%) responded completely (CR), 2 (14.2\%) responded partially and $3(21.4 \%)$ responded as SD while in 12 patients with tumour size $>4 \mathrm{~cm}, 4(33.3 \%)$ responded completely (CR) and rest $8(66.6 \%)$ response was partial (PR).
\end{abstract}

Conclusions: Response to chemotherapy was modified by pre-treatment volume of the tumour.

Keywords: Carcinoma cervix, Downstaging, Neoadjuvant chemotherapy, Operability, Radiotherapy, Tumour response, Tumour size

\section{INTRODUCTION}

Most patients in the developed world present with early disease either confined to the cervix or with limited extension beyond it (International Federation of Gynecology and obstetrics (FIGO) stage IB1-IIA). While in the developing country patients present too late either as a case of locally advanced carcinoma cervix (FIGO Stage IIB, III, and IVA) or with distant metastases. For early stage (FIGO stage Ib to IIa) standard treatment is radical radiotherapy or radical hysterectomy with node dissection, each giving 5-year survival rates of around $80-90 \% .{ }^{1}$ Radical radiotherapy, comprising external beam and intracavitary treatment, tends to be the treatment of choice for locally advanced disease (FIGO Stage IIB, III and IVA) and offers an alternative to radical surgery for patients with tumor larger than $4 \mathrm{cms}$ confined to the cervix (Stage IB bulky. ${ }^{2} 5$ year survival using radiotherapy ranged from around $60 \%$ for patient with stage IIB disease to approximately $20 \%$ for patients with stage IV disease. 
In order to improve the survival, various techniques have been used including radio-sensitization, hyperbaric oxygen, altered fractionation schedule and combination of therapy viz. Surgery, radiotherapy and chemotherapy.

Recently neoadjuvant chemotherapy has started being considered for advanced stage of carcinoma cervix. Neoadjuvant chemotherapy arrests growth and controls micro metastases and may improve success of subsequent surgery or radiotherapy. It has also been observed that response to neoadjuvant chemotherapy is predictive of the response to subsequent radiotherapy. The patients who responds to neoadjuvant chemotherapy have a significantly improved disease - free survival rate compared to those who do not respond..$^{3,4}$

\section{Advantages of neoadjuvant chemotherapy are}

- Drug delivery to pelvic tumour is optimal with neoadjuvant chemotherapy since tumour vascular supply has not been damaged by any previous pelvic interference and the tumor may be intrinsically more chemo sensitive prior to definitive radiotherapy. ${ }^{5}$

- Decrease in the primary tumour bulk by neoadjuvant chemotherapy makes surgery easier. In some otherwise inoperable tumour it makes them surgically removable (down staging). ${ }^{5}$

- When radiotherapy is scheduled as the main treatment modality; better dose distribution of brachytherapy can be expected after neoadjuvant chemotherapy. ${ }^{5}$

- Less radiotherapy toxicity is observed when chemotherapy is given prior to radiotherapy rather than concomitantly. ${ }^{5}$

- When NACT is followed by surgery, an absolute increase of $15 \%$ in five-year survival over radiation alone is seen. ${ }^{6}$

\section{Response to neoadjuvant chemotherapy}

- $\quad$ Response to neoadjuvant chemotherapy is affected by several factors. Tumor size and parametrial involvement have been reported to be important predictor of NACT response.

\section{METHODS}

This is a prospective cohort study, it was carried out in the Department of Obstetrics and Gynaecology with the collaboration of Department of Radiotherapy, Chhatrapati Shahuji Maharaj Medical University Lucknow for a period of 1-year august 2010 to august 2011. 26 patients admitted in the department of obstetrics and gynaecology with histologically proven locally advanced carcinoma cervix were studied.

\section{Inclusion criteria}

- Women with histopathologically proven carcinoma cervix, stage IIA, IIB, IIIA, IIIB
- $\quad$ Good performance status (KPS $>70)$

- Normal prechemotherapy tests including haemogram, liver function test, kidney function test, serum electrolyte

- Informed consent for participation in the study.

\section{Exclusion criteria}

- Deranged prechemotherapy tests

- Systemic illness-cardiac, respiratory and hepatorenal

- Prior radiotherapy or chemotherapy

- Pre-existing neuropathy of any cause

- Mental illness

- Pregnancy and lactation

- Patient with evidence of visceral, skeletal or extra abdominal nodal metastasis.

After taking an informed consent, a detailed history with special reference to lower genital tract infection, personal hygiene, personal history with special reference to sexual habit was taken. A thorough general and systemic examination was done along with evaluation of performance status based on Karnofsky performance status (Table 1).

Table 1: Karnofsky performance status.

\begin{tabular}{|ll|l|}
\hline Grade & ECOG & $\begin{array}{l}\text { Karnofisy } \\
\text { scale }\end{array}$ \\
\hline 0 & Asymptomatic & 100 \\
\hline 1 & Syptomatic, full activity & $80-90$ \\
\hline 2 & $\begin{array}{l}\text { Symptomatic, spends less than } \\
50 \% \text { of time in bed }\end{array}$ & $50-70$ \\
\hline 3 & $\begin{array}{l}\text { Symptomatic spends more than } \\
50 \% \text { 0f time in bed }\end{array}$ & $30-40$ \\
\hline 4 & Bedridden & $10-20$ \\
\hline
\end{tabular}

Gynaecological examination including per abdominal, pervaginal and per rectal examination, blood investigation, IVP (intravenous pyelography), cystoscopy, X-ray chest and ultrasound lower abdomen and pelvis and whenever possible CT scan and MRI was done. Clinical staging was done according to current FIGO classification in all cancer cervix patients.

\section{In all cases following chemotherapy regimen was given.}

Cisplatin $75 \mathrm{mg} / \mathrm{m}^{2}$ and paclitaxel $135 \mathrm{mg} / \mathrm{m}^{2}$ on day one with supportive therapy including methyl prednisolone, chlorpheniramine, ranitidine and ondensetrone 30 minute before the treatment delivery along with $\mathrm{I} / \mathrm{V}$ hydration was given at 14 days interval with routine monitoring, up to maximum of three courses.

Evaluation of operability status was done two weeks after second course of chemotherapy. Those found operable were taken up for radical hysterectomy and rest were given $3^{\text {rd }}$ course of chemotherapy. After two weeks of $3^{\text {rd }}$ 
course again operability assessment was done and patient was taken up either for surgery or radiotherapy.

\section{Efficacy of neoadjuvant chemotherapy was studied as follows}

- $\quad$ Operability status: Assessment of operability status was done with perspeculum, pervaginal, perrectal examination. Patient with growth confined to the cervix, without parametrial or vaginal extension was considered operable

- Down staging of disease

- Objective response regarding tumour size

WHO criteria for tumor response was used (Table 2).

Table 2: WHO criteria for tumor response.

\begin{tabular}{|c|c|}
\hline & WHO \\
\hline \multirow{2}{*}{ Measurability } & Measurable, bidimensional \\
\hline & Non-measurable/evaluable \\
\hline \multicolumn{2}{|l|}{ Objective response } \\
\hline $\begin{array}{l}\text { Complete response } \\
(\mathrm{CR})\end{array}$ & $\begin{array}{l}\text { Disappearance of all known } \\
\text { lesion (s); confirmed at } 4 \text { weeks }\end{array}$ \\
\hline $\begin{array}{l}\text { Partial response } \\
\text { (PR) }\end{array}$ & $\begin{array}{l}\text { At least } 50 \% \text { decrease; } \\
\text { confirmed at } 4 \text { weeks }\end{array}$ \\
\hline Stable disease (SD) & Neither PR nor PD criteria met \\
\hline $\begin{array}{l}\text { Progressive disease } \\
\text { (PD) }\end{array}$ & $\begin{array}{l}25 \% \text { increase; no CR, PR or SD } \\
\text { documented before increased } \\
\text { disease, or new lesion (s) }\end{array}$ \\
\hline
\end{tabular}

\section{RESULTS}

A total of 26 subjects in different stages of carcinoma cervix were enrolled in the present study. $57.69 \%$ patient belong to stage IIB and $42.31 \%$ belong to stage IIB. Histopathological results of the tumour showed that out of $26,13(50 \%)$ were squamous cell keratinizing and other $50 \%(\mathrm{n}=13)$ were squamous cell non-keratinizing in nature. Out of 26 patient $45.4 \%<40$ years and54.6\% > 40 year.

It was observed that out of 14 patients who had tumour size <4 cm, 9 (64.2\%) responded completely (CR), 2 $(14.2 \%)$ responded partially and $3(21.4 \%)$ responded as SD while in 12 patients with tumour size $>4 \mathrm{~cm}, 4$ (33.3\%) responded completely (CR) and rest 8 (66.6\%) response was partial (PR). The difference was statistically significant (Table 3 ).

Table 4 clearly shows that size of tumour at initial stage (before chemotherapy) was an important factor in down grading it through chemotherapy. As discussed above the response of tumour size $<4 \mathrm{~cm}$ was more as compared to that of $>4 \mathrm{~cm}$ tumour size. Down staging of tumour was observed in $64.2 \%$ of tumours $<4 \mathrm{~cm}$ as compared to $33.3 \%$ with a size of $>4 \mathrm{~cm}$. $50 \%$ tumours $<4 \mathrm{~cm}$ attained a stage where operation could be performed and this stage could only be obtained in $25 \%$ patients with tumour size $>4 \mathrm{~cm}, \mathrm{CR}$ (complete response) was observed in $64.2 \%$ in patients with tumour size $<4 \mathrm{~cm}$ as compared to $33.3 \%$ in patients with tumour size $>4 \mathrm{~cm}$.

It was observed that after 3 cycle of neoadjuvant chemotherapy $9(64.2 \%)$ patients with tumour size $<4 \mathrm{~cm}$ down staged as compared to only $4(33.3 \%)$ with tumour size $>4 \mathrm{~cm}$. The difference in improvement in patients with tumour size $<4 \mathrm{~cm}$ was just double as compared to that with tumour size $>4 \mathrm{~cm}$, but this difference was statistically non-significant $(\mathrm{p}=0.116)$ (Table 5).

It was observed that $7(50 \%)$ patients with tumour size $<4$ $\mathrm{cm}$ attained operable stage as compared to only $3(25 \%)$ with tumour size $>4 \mathrm{~cm}$, but this difference was statistically non-significant (Table 6).

Table 3: Tumour response in relation to pre chemotherapy size of the tumour.

\begin{tabular}{|lllllllll|}
\hline \multirow{2}{*}{ Mean size } & \multicolumn{2}{l}{ Tumour response } & & & & & PD & \\
& CR & & PR & & SD & No. & \% \\
\hline & No & \% & No & \% & No. & \% & No. \\
\hline$>4 \mathrm{~cm}(\mathrm{n}=14)$ & 9 & $64.2 \%$ & 2 & $14.2 \%$ & 3 & $21.4 \%$ & 0 & $0 \%$ \\
\hline
\end{tabular}

$x^{2}-8.419 ; \mathrm{p}=0.014$.

Table 4: Neoadjuvant chemotherapy response in relation to pre chemotherapy sizes of tumour.

\begin{tabular}{|c|c|c|c|c|c|c|c|c|c|c|c|c|c|c|c|c|}
\hline \multirow{3}{*}{$\begin{array}{l}\text { Mean } \\
\text { size }\end{array}$} & \multicolumn{4}{|c|}{ Down staging } & \multicolumn{4}{|c|}{ Operability } & \multicolumn{8}{|c|}{ Tumour response } \\
\hline & \multicolumn{2}{|c|}{ Observed } & \multicolumn{2}{|c|}{ Not observed } & \multicolumn{2}{|c|}{ Operable } & \multicolumn{2}{|c|}{ Inoperable } & \multicolumn{2}{|c|}{ CR } & \multicolumn{2}{|c|}{ PR } & \multicolumn{2}{|l|}{ SD } & \multicolumn{2}{|l|}{ PD } \\
\hline & No. & $\%$ & No. & $\%$ & No & $\%$ & No. & $\%$ & No & $\%$ & No & $\%$ & No. & $\%$ & No. & $\%$ \\
\hline $\begin{array}{l}=<4 \mathrm{~cm} \\
(\mathrm{n}=14)\end{array}$ & 9 & 64.2 & 5 & 35.7 & 7 & 50 & 7 & 50 & 9 & 64.2 & 2 & 14.2 & 3 & 21.4 & 0 & 0 \\
\hline $\begin{array}{l}>4 \mathrm{~cm} \\
(\mathrm{n}=12)\end{array}$ & 4 & 33.3 & 8 & 66.6 & 3 & 25 & 9 & 75 & 4 & 33.3 & 8 & 66.6 & 0 & 0 & 0 & 0 \\
\hline
\end{tabular}


Table 5: Correlation between pre-chemotherapy size of the tumor and down staging.

\begin{tabular}{|lllll|}
\hline \multirow{2}{*}{ Mean size } & \multicolumn{3}{l}{ Down staging } \\
\cline { 2 - 5 } & Observed & \% & Not observed \\
\cline { 2 - 5 } & No. & $64.2 \%$ & 5 & $35.7 \%$ \\
\hline$>4 \mathrm{~cm}(\mathrm{n}=12)$ & 9 & $33.3 \%$ & 8 & $66.6 \%$ \\
\hline
\end{tabular}

$x^{2}=2.476 ; \mathrm{p}=0.116$.

Table 6: Correlation between pre chemotherapy size of the tumour and change in operability status.

\begin{tabular}{|c|c|c|c|c|}
\hline \multirow{3}{*}{ Mean size pre NACT } & \multicolumn{4}{|c|}{ Post therapy operability } \\
\hline & \multicolumn{2}{|c|}{ Operable } & \multicolumn{2}{|c|}{ Inoperable } \\
\hline & No. & $\%$ & No. & $\%$ \\
\hline$=<4 \mathrm{~cm}(\mathrm{n}=14)$ & 7 & $50 \%$ & 7 & $50 \%$ \\
\hline$>4 \mathrm{~cm}(\mathrm{n}=12)$ & 3 & $25 \%$ & 9 & $75 \%$ \\
\hline
\end{tabular}

$x 2=1.706 ; \mathrm{p}=0.191$

Table 7: Correlation between pretherapy size and stage of disease with tumour response.

\begin{tabular}{|c|c|c|c|c|c|c|c|c|c|}
\hline \multirow{3}{*}{$\begin{array}{l}\text { Pre chemotherapy } \\
\text { stage }\end{array}$} & \multirow{3}{*}{$\begin{array}{l}\text { Pre chemotherapy } \\
\text { mean size }\end{array}$} & \multicolumn{8}{|c|}{ Tumour response after NACT } \\
\hline & & \multicolumn{2}{|l|}{ CR } & \multicolumn{2}{|c|}{ PR } & \multicolumn{2}{|l|}{ SD } & \multicolumn{2}{|l|}{ PD } \\
\hline & & No. & $\%$ & No. & $\%$ & No. & $\%$ & No. & $\%$ \\
\hline \multirow{2}{*}{ IIB } & $=<4 \mathrm{~cm}(\mathrm{n}=8)$ & 6 & $75 \%$ & 0 & $0 \%$ & 2 & $25 \%$ & 0 & $0 \%$ \\
\hline & $>4 \mathrm{~cm}(\mathrm{n}=7)$ & 3 & $42.8 \%$ & 4 & $57.14 \%$ & 0 & $0 \%$ & 0 & $0 \%$ \\
\hline \multirow{2}{*}{ IIIB } & $=<4 \mathrm{~cm}(\mathrm{n}=6)$ & 3 & $50 \%$ & 2 & $33.3 \%$ & 1 & $16.6 \%$ & 0 & $0 \%$ \\
\hline & $>4 \mathrm{~cm}(\mathrm{n}=5)$ & 1 & $20 \%$ & 4 & $80 \%$ & 0 & $0 \%$ & 0 & $0 \%$ \\
\hline
\end{tabular}

Table 8: Overall down staging observed after neoadjuvant chemotherapy.

\begin{tabular}{|c|c|c|c|c|}
\hline \multirow{2}{*}{ Pre-therapy stage } & \multicolumn{3}{|c|}{ Post-therapy stage } & \multirow{2}{*}{ Down staging observed } \\
\hline & IIIB & IIB & IB & \\
\hline Stage IIB $(n=15)$ & Not applicable & $6(40 \%)$ & $9(60 \%)$ & $9(60 \%)$ \\
\hline Stage IIIB $(n=11)$ & $7(63.63 \%)$ & $3(27.27 \%)$ & $1(9.09 \%)$ & $4(36.36 \%)$ \\
\hline Total $(n=26)$ & & & & $13(50 \%)$ \\
\hline
\end{tabular}

$x 2=1.418 ; \mathrm{p}=0.233$.

Table 9: Post neoadjuvant chemotherapy operability in cases.

\begin{tabular}{|lll|}
\hline Pre neoadjuvant chemotherapy & Post neoadjuvant chemotherapy \\
\hline Stage & Operable & Inoperable \\
\hline IIB $(n=15)$ & $9(60 \%)$ & $6(40 \%)$ \\
\hline IIIB $(n=11)$ & $1(9.09 \%)$ & $10(90.91 \%)$ \\
\hline Total $(\mathbf{n}=\mathbf{2 6})$ & $\mathbf{1 0}(\mathbf{3 8 . 4 \% )}$ & $\mathbf{1 6}(\mathbf{6 1 . 5 \% )}$ \\
\hline
\end{tabular}

$x 2=6.949 \mathrm{p}=0.008$.

Tumour size is very important predictor for chemotherapy response. A patient of same stage and having tumour less than $4 \mathrm{~cm}$ respond more as compared to tumour more than $4 \mathrm{~cm}$ (Table 7).

After 3 cycle of neoadjuvant chemotherapy downstaging observed in $60 \%$ patient of stage IIB and $36.36 \%$ of stage IIIB. Thus, overall downstaging observed in $50 \%$ patient (Table 8).
After neoadjuvant chemotherapy, there were 10 patients who became operable, of these 9 belonged to stage IIB and 1 belonged to stage IIIB before therapy.

Before chemotherapy there were 11 patients of Stage IIIB, 1 (9.09\%) was operable, and 10 (90.91\%) were inoperable and there were 15 patients of stage IIB, 9 $(60 \%)$ were operable while $6(40 \%)$ remained inoperable. 
On comparing the data statistically, significant change in status of patients was observed $(\mathrm{p}=0.008)$ (Table 9$)$.

\section{Table 10: Overall tumour response after neoadjuvant chemotherapy.}

\begin{tabular}{|lll|}
\hline Finding & No. of patients & Percentage \\
\hline Complete response & 13 & 50 \\
\hline Partial response & 10 & 38.4 \\
\hline Stable disease & 3 & 11.5 \\
\hline Progressive disease & 0 & 0 \\
\hline
\end{tabular}

Overall response observed in present study was $88.4 \%$, complete response was observed in $13(50 \%)$ patients, 10 $(38.4 \%)$ patients showed partial response. Disease remained stable in $3(11.5 \%)$ patients. Progression of the disease was not observed (Table 10).

\section{DISCUSSION}

Currently, cisplatin-based chemo radiation is the standard of care for locally advanced carcinoma cervix. However, the prognosis has remained unsatisfactory apart from increased toxicity. Combination of 2 or more treatment modalities such as surgery, radio therapy, and chemotherapy are the main strategies to improve the cure rates. Among these multimodality strategies there has been keen interest in neoadjuvant chemotherapy prior to definitive surgery or radio therapy. Several pilot investigations with encouraging results have promoted interest in this treatment modality. More than two decades have passed since neoadjuvant chemotherapy was introduced in the clinical practice. Several open questions still remain unanswered and in particular no standard drug regimen is unanimously accepted. There are many regimens for neoadjuvant chemotherapy in carcinoma cervix. PVB (cisplatin, vincristin, bleomycin) BOMP (bleomycin, ifosamide, cisplatin), BIP (bleomyin, ifosamide, cisplatin) and quick VBP regimens developed by Sardi et al, and modified VBP regimen consist of (vincristin $1 \mathrm{mg} / \mathrm{m}^{2}$ on day 1 and cisplatin $50 \mathrm{mg} / \mathrm{m}^{2}$ on day 1 , bleomycin $25 \mathrm{mg} / \mathrm{m}^{2}$ on day 1 an day 2) on weekly basis for 3 courses (Taneja A), TP (cisplatin $75 \mathrm{mg} / \mathrm{m}^{2}$, paclitaxel $175 \mathrm{mg} / \mathrm{m}^{2}$ ) every 3 week maximum of 3 courses (Fossati R). ${ }^{7,8}$ MVC (mitomycin-c $10 \mathrm{mg} / \mathrm{m}^{2}$, vincristin $1 \mathrm{mg} / \mathrm{m}^{2}$, and cisplatin $75 \mathrm{mg} / \mathrm{m}^{2}$ ) every 3 week for 3 courses. (Knagnam -KU). Thus most of the regimen are repeated for 2 or 3 courses and clinical response rate increased with the number of chemotherapeutic courses (Kim et al). ${ }^{9}$ However, efficacy of the regimen is usually determined within 2 to 3 courses and protected pretreatment is not desirable .In the present study cisplatin $75 \mathrm{mg} / \mathrm{m}^{2}$ and paclitaxel $135 \mathrm{mg} / \mathrm{m}^{2}$ on day 1 at 14 days interval for up to 3 courses were given.

Traditionally chemotherapeutic regimens have been cycled 3 weekly and require at least 9 to 12 weeks before the patient can be considered for definitive therapy (Kumar L). ${ }^{10}$ A "Quick -Cycle" regime which is cycled weekly not only decreases the time to definitive therapy but also prevents the rapid regrowth of tumour cells .No study has reported the increase of side effects with subsequent radiotherapy (Kumar L). In India at certain places, due to paucity of enough radiotherapy facilities a waiting period of 4 to 6 week exists for definitive radiotherapy and this may be critical to the outcome of the disease. Therefore, quick cycle chemotherapy, during this period may form an important adjunct without hampering conventional treatment. Trial using chemotherapy cycle length shorter than 14 days (HR $=0.83,95 \% \mathrm{CI}=0.69$ to $1.0, \mathrm{p}=0.046)$ or cisplatin dose intensities greater than $25 \mathrm{mg} / \mathrm{m}^{2}$ tended to show an advantage for neoadjuvant chemotherapy on survival. In contrast trials using cycle length longer than 14 days $(\mathrm{HR}=1.25,95 \% \mathrm{CI}=1.07$ to $1.46 \mathrm{P}=0.005)$ or cisplatin dose intensities lower than $25 \mathrm{mg} \%$ per weeks ( $\mathrm{HR}=1.35$, $95 \mathrm{CI}=1.11$ to $1.14 \mathrm{p}=0.0002$ ) tended to show $\mathrm{a}$ detrimental effect of neoadjuvant chemotherapy on survival. In present study cisplatin dose intensity was 75 $\mathrm{mg} / \mathrm{m}^{2}$ and cycle length was not longer than 14 days. Patients were followed up at the end of $2^{\text {nd }}$ and $3^{\text {rd }}$ cycle of chemotherapy. Change in the stage of cancer, assessment regarding operability, and decrease in mean tumour volume and tumor response was made.

Overall response observed in present study was 88.4, complete response was observed in $13(50 \%)$ patients, 10 $(38.4 \%)$ patients showed partial response and disease remained stable in $3(11.5 \%)$ patients. Dottino et al, observed $35 \%$ complete response and $65 \%$ partial response. Similarly, Park et al observed $87 \%$ overall response and Duenar $\mathrm{A}$ et al found $9 \%$ complete response and $86 \%$ partial response. While Taneja A et al observed $8.7 \%$ complete response and $39.9 \%$ partial response (Table 11).

Table 11: Tumour response.

\begin{tabular}{|c|c|c|c|}
\hline Study & Overall response & CR & PR \\
\hline Dottino et $\mathrm{al}^{11}$ & $100 \%$ & $35 \%$ & $65 \%$ \\
\hline Park et $\mathrm{al}^{12}$ & $87 \%$ & - & - \\
\hline Duenar A et al & $95 \%$ & $9 \%$ & $86 \%$ \\
\hline Taneja A & $47.8 \%$ & $8.7 \%$ & $39.1 \%$ \\
\hline Present study & $88.4 \%$ & $50 \%$ & $38.4 \%$ \\
\hline
\end{tabular}

Benedetri-Panici et al, studied 75 patients with bulky stage Ib to IIIb disease and found that tumour size of $>5$ $\mathrm{cm}$ and complete bilateral parametrial involvement were associated with decreased response to NACT. ${ }^{13}$ Sardi et al, commented that response to NACT strongly associated with the initial volume. The critical pretreatment volume for response was $84 \%(4.85 \mathrm{~cm}$ in diameter). Similar results were obtained in present study, in patients with tumour size $<=4 \mathrm{~cm}$ complete response (CR) were observed in $64.2 \%$ while in patients with tumour size $>4 \mathrm{~cm}$ complete response $(\mathrm{CR})$ was seen in $33.3 \%$ patients. Though there were difference in response in patients with tumour size $<4 \mathrm{~cm}$ and those with $>4 \mathrm{~cm}$ but this difference was statistically non-significant. This 
indicates that studies with larger sample size should be conducted to confirm the same.

Patients having similar tumour size but belonging to higher stage associated with decrease response to NACT. In present study similar results were obtained complete response $(\mathrm{CR})$ in tumour size $<=4 \mathrm{~cm}$ was $75 \%$ in stage IIb while $50 \%$ in stage IIIb when tumour size $>4 \mathrm{~cm}$ complete response was $42.8 \%$ in stage IIb while $20 \%$ in stage IIIb.

After 3 cycles of NACT there were $10(38.4 \%)$ patients who were operable, of these 10 patients 9 belonged to stage IIB, and 1 belonged to stage IIIB. Before chemotherapy there were 15 patients of stage IIB out of which $9(60 \%)$ were became operable and $6(40 \%)$ of patients remained inoperable. Before chemotherapy there were 11 patients of stage IIIB, $1(9.09 \%)$ was operable after 3 cycle while $10(90.01 \%)$ were inoperable. On comparing data statistically, significant change in status of patients was observed. While Duenar A et al observed 95\% operability and A Taneja observed $100 \%$ operability and Salvaggi et al found $86 \%$ operability in their study (Table 12). ${ }^{14}$

Table 12: Operability.

\begin{tabular}{|ll|ll|}
\hline Study & Operability & Enrolled stage & Chemotherapy regimen \\
\hline Duenar A et al & $95 \%$ & Ib-IIIb & GP every 3 week for 3 cycle \\
\hline Taneja A et al & $100 \%$ & I-IV & VBP weekly for 3 cycles \\
\hline Selvaggi et al ${ }^{14}$ & $86 \%$ & I-III & - \\
\hline Present study & $38.4 \%$ & IIb-IIIb & TP every 14 days for 3 cycles \\
\hline
\end{tabular}

\section{CONCLUSION}

Response to chemotherapy was modified by pretreatment volume of the tumour. In patients with tumour size $<=4 \mathrm{~cm}$ complete response was observed in $64.2 \%$ while in patients with tumour size $>4 \mathrm{~cm}$ complete response was seen in only $33.35 \%$ of patients. Patients having similar tumour size but belonging to higher stage was associated with decrease response to NACT.

\section{Funding: No funding sources}

Conflict of interest: None declared

Ethical approval: The study was approved by the Institutional Ethics Committee

\section{REFERENCES}

1. Benedet J, Oddicino F, Mainsonneuver P. Carcinoma of the cervix uteri. J Epidemiol Biostat. 1998;3:5-34.

2. Eifel PJ, Berek JS. Gynecologic Cancer. Section 2. Cancer of the cervix, vagina, vulva, In: Devita VTJr, Hellman S, Rosenberg SA editor (s) Cancer principle and practice of oncology $6^{\text {th }}$ edition volume 2 Philadelphia: Lippincort-Raven; 2001:1526-1556.

3. Kirsten F, Atkinson KH, Coppleson JVM, Elliot PM, Green D, Houghton R, et al. Combination chemotherapy followed by surgery or radiotherapy in patients with locally advanced cervical caner. Brit J Obstet Gyneccol. 1987;94:583-8.

4. Kumar L, Kausal R, Nandy M. Chemotherapy followed by radiotherapy versus radi cervicotherapy alone in locally advanced cervical cancer:a randomized study. Gynecol Oncol. 1994;54:307.
5. Sugimori H, Iwaska T, Department of obstetrics and Gynecology, Saga Medical School, Saga Japan. Int J Clin Oncol. 1972;2:183-8.

6. Unided de investigation, Bimedia en cancer Instituto National de cancerlogia, instituto de investigations, Biomedicas UNAM, Tipan 14080, Mexico Cancer Treatment Reviews. 2003;29:389-99.

7. Sardi J, Sananes C, Giaroli A, Maya G, Di Paola G. Neoadjuvant chemotherapy in locally advanced carcinoma of the cervix uteri. Gynecol Oncol. 1990;38:486-93.

8. Taneja A, Rajaram S, Agarwal S, Singh KC, Sahni S, Goel N. Indian J Pharmacol. 2005;37(5):320-4.

9. Kim DS, Moon H, Kim KT, Hwant YY, Cho SH, KIM. Two-year survival: preoperative adjuvant chemotherapy in the treatment of cervical cancer stage Ib and II with bulky tumor. Gynecol Oncol. 1989;33:225-30.

10. Kumar L, Kaushal R, Nandy M. Chemotherapy followed by radiotherapy versus radiotherapy alone in locally advanced cervical cancer: a randomised study. Gynecol Oncol. 1994;54:307-15.

11. Dottino PR, Plaxe SC, Beddoe AM, Johson C, Cohen C. Induction chemotherapy followed by radical surgery in cervical cancer. Cancer. 1991;67:372-9.

12. Park TK Choi DH, Kim SN, Lee H, Kim YT, KIM GE, et al. Role of induction chemotherapy in invasive cervical cancer. Gynecol Oncol. 1991;41:107-12.

13. Benedetti -panici P, Scambia G, Baiocchi G, Greggi S, Ragusa G, Gallo A, et al. Neoadjuvant chemotherapy and radical surgery in locally advanced cervical cancer 1991;67:372-9. 
14. Selvaggi L, Loizzi V, Di Gillo, AR. Nardelli C, Cantatore C. Neoadjuvant chemotherapy in cervical cancer: a 67 patients experience. Int J Gynecol Cancer. 2006;16(2):631-7.
Cite this article as: Ahirwar N. Size of cervical lesion in locally advanced carcinoma cervix and response to neoadjuvant chemotherapy. Int J Reprod Contracept Obstet Gynecol 2019;8:4254-60. 